\title{
Processos de tratamento de resíduos de cocheira e a redução ou eliminação de ovos e larvas infectantes do gênero Strongylus spp.
}

\author{
Treatment procedures for stable waste and reduction or elimination of infective \\ eggs and larvae of the genus Strongylus spp.
}

\author{
Keila Youko Fujii ${ }^{\text {* }}$, João Ricardo Dittrich ${ }^{1}$, Edilene Alcântara de Castro², Emanuel Orestes da Silveira1

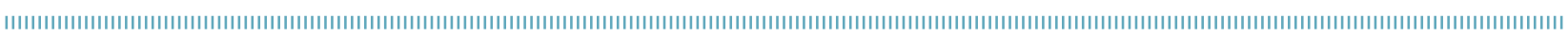

\begin{abstract}
RESUMO: Objetivou-se neste trabalho caracterizar os processos de compostagem de resíduos de cocheira e avaliar a eficiência deles na reduçáo ou na eliminaçáo de ovos e larvas infectantes de Strongylus spp. Os tratamentos de compostagem utilizados foram: aberta sem revolvimento em menor volume (CASRm) e maior volume (CASRM); aberta com revolvimento em menor volume (CAm) e maior volume (CAM); e anaeróbica em biodigestor (CF), em três repetiçóes. As variáveis monitoradas foram temperatura, umidade, presença de parasitos no início e no final do período experimental. No primeiro dia de avaliaçáo, a temperatura no centro das CASRM e CAM atingiu seu máximo, próximo a $60^{\circ} \mathrm{C}$, permanecendo acima de $50^{\circ} \mathrm{C}$ nos três primeiros dias. No restante do período experimental, manteve-se ao redor de $30^{\circ} \mathrm{C}$. Antes da aplicação dos tratamentos, observou-se elevada contaminação por larvas de Strongylus spp. (25,3 larvas por grama de resíduo). Ao final do período experimental, considerando o centro das compostagens, houve redução das larvas infectantes de terceiro estágio, da seguinte ordem: 97\% (CAM), 87\% (CAm), 90\% (CASRM) e $100 \%$ (CF), e de apenas $26 \%$ para o tratamento CASRm. Na parte superficial das compostagens não foram encontrados parasitas em nenhum dos tratamentos. A umidade superficial do composto no final do experimento foi de aproximadamente 17 a 30\%, e a interna, de 40 a $60 \%$. Ovos de helmintos permaneceram viáveis, mesmo após o processo de compostagem e o tratamento térmico. Os resultados indicam que com a simples disposição dos resíduos de cocheira sem manejo adequado e em pequenos volumes, não há eliminação total de ovos e de larvas infectantes de Strongylus spp.
\end{abstract}

PALAVRAS-CHAVE: compostagem; larvas infectantes; temperatura.
ABSTRACT: The objective of this study was to characterize the processes of composting stable waste and to evaluate the efficiency in the reduction or elimination of infective eggs and larvae of Strongylus spp. The composting treatments were: open, without rotation, in a smaller volume (CASRm) and larger volume (CASRM); open, with rotation, in a smaller volume (CAm) and a larger volume (CAM), and anaerobic in biodigester $(\mathrm{CF})$, in three replicates. The monitored parameters were temperature, moisture and presence of parasites in the beginning and at the end of the experimental period. Temperature at the center of CAM and CASRM reached ita peak on the first day, of approximately $60^{\circ} \mathrm{C}$, being higher than $50^{\circ} \mathrm{C}$ only in the first three days. In the other treatments, the maximum temperature was around $30^{\circ} \mathrm{C}$. Before treatments were applied, it was possible to observe high levels of contamination by larvae of Strongylus spp. (with 25.3 larvae per gram). The reduction of infective third stage larvae in the compost at the end of the experiment was of $97 \%$ (CAM), $87 \%$ (CAm), 90\% (CASRM), 100\% (CF), and 26\% for the CASRm treatment. On the outside it was not possible to detect the presence of the parasite. The humidity outside the compound at the end of the experiment was of approximately 17 to $30 \%$, and internally, of 40 to $60 \%$. Helminth eggs remained viable even after the composting process and heaingt treatment. The results indicate that the mere provision of stable waste without the proper handling and in small volumes does not lead to the total elimination of eggs and infective larvae of Strongylus spp.

KEYWORDS: composting; infective larvae; temperature.

\footnotetext{
'Departamento de Zootecnia; Universidade Federal do Paraná (UFPR) - Curitiba (PR), Brasil.

${ }^{2}$ Departamento de Patologia Básica; UFPR - Curitiba (PR), Brasil.

*Autor correspondente: keilafujii@me.com

Recebido em: 04/05/2012. Aceito em: 27/05/2014
} 


\section{INTRODUÇÃO}

A equinocultura é uma atividade que produz grandes quantidades de resíduos, principalmente provenientes do manejo de cocheiras, como fezes, urina e cama (serragem, maravalha, palhas). Locais como hípicas, hipódromos e regimentos de cavalaria, geralmente localizados em grandes centros urbanos, não apresentam recursos nem locais físicos apropriados para o tratamento correto desses resíduos; consequentemente, não há padronização de manejo. Quando dispostos inadequadamente no meio ambiente, trazem consequências indesejáveis, como problemas de controle de enfermidades parasitárias nos animais, riscos de contaminação ambiental e problemas de saúde pública.

Para Strauch (1987), praticamente todos os agentes causais transmissíveis podem ser encontrados nos dejetos e em seus subprodutos (chorume), ressaltando que a capacidade de sobrevivência dos agentes no ambiente é muito variada, especialmente nos dejetos e resíduos de animais, a depender de vários fatores que os condicionam e predispóem. Este fato constitui grave problema sanitário devido à possibilidade de contaminaçáo do homem e dos animais quando em contato direto com os resíduos ou por meio dos vetores biológicos, como moscas, mosquitos, água e alimentos contaminados (via indireta) (Pereira Neto; Lelis, 2001).

As formas de tratamento dos dejetos empregados na produção animal antes de serem despejados no meio ambiente podem ser física, química e bioquímica. O tratamento físico consiste em separar as partículas contidas nos dejetos líquidos, obtendo-se dois produtos: fração líquida e fração sólida, por meio da decantação, peneiramento, centrifugaçấo ou desidratação. As técnicas de tratamento químico ocorrem pela adição de produtos químicos, e a açáo desses produtos pode se dar de três formas diferentes: bloqueio das fermentaçôes indesejáveis, seleção bacteriana com orientação específica de fermentação e sobreposiçẫo de odores. Os tratamentos bioquímicos podem ser a compostagem, quando ocorre a degradação da matéria orgânica pelo processo aeróbio; lagoas de estabilizaçáo (facultativas ou aeradas); diques de oxidação, que é um sistema com aeração artificial; câmaras de aeração em circuito fechado ou contínuo; lagoas anaeróbias e digestores anaeróbios (LovatTo et al., 1997).

A compostagem é uma das principais formas para o tratamento adequado dos resíduos de origem animal; tem baixo custo e é o mais utilizado pelo homem. É um dos mais antigos processos de reciclagem de resíduos orgânicos grosseiros, como palha e estrume, em materiais orgânicos utilizáveis na agricultura. A temperatura do processo de compostagem, assim como a umidade e o $\mathrm{pH}$, determinará a sucessão das populaçôes parasitológicas e sua representividade nas fases de degradação, sendo elas a mesofílica e a termofílica, verificando a eficiência de sanitização do material a ser compostado.

Porém, os principais problemas relacionados à compostagem é à contaminaçáo devido à presença de alguns elementos químicos, como metais pesados e micro-organismos patogênicos, que não são eliminados durante esse processo. As causas da ineficiência dos processos desse tipo de tratamento, no que diz respeito à eliminaçáo de micro-organismos patogênicos, podem estar relacionadas ao método utilizado, à eficácia das reaçôes biofísicas e bioquímicas da degradação da matéria orgânica e às interpretaçóes errôneas sobre o tempo e temperatura necessários para a inativação desses agentes contaminantes (Pereira Neto; Lelis, 2001).

Diante do exposto, o presente trabalho objetivou caracterizar os processos de compostagem de resíduos de cocheira e avaliar sua eficiência para a reduçấo ou eliminação de ovos e larvas infectantes de Strongylus spp.

\section{MATERIAL E MÉTODOS}

O experimento foi implantado e conduzido no período de 9 de agosto a 20 de setembro de 2011, com resíduos de cocheiras (fezes, urina e serragem) de cavalos pertencentes ao regimento da Polícia Montada Coronel Dulcídio (RPMon), em Curitiba (PR). O material recém-coletado no momento da limpeza e troca de camas de oito cocheiras foi transportado para um galpão fechado no Departamento de Zootecnia da Universidade Federal do Paraná (UFPR).

Os resíduos foram organizados em formas de compostagem (aberta - aeróbia e fechada - anaeróbia) de diferentes volumes. Os tratamentos foram: compostagem aberta sem revolvimento em menor volume (CASRm), compostagem aberta sem revolvimento em maior volume (CASRM), compostagem aberta com revolvimento em menor volume (CAm), compostagem aberta com revolvimento em maior volume (CAM) e compostagem anaeróbia em biodigestor (CF).

Para cada tratamento foram realizadas três repetiçóes, contendo $9,5 \mathrm{~kg}$ de resíduos para os de menor volume e $152 \mathrm{~kg}$ para os de maior volume, que foram depositados sobre bandejas de metal e isolados do cháo com um isopor. A altura e a largura das composteiras foram de aproximadamente $1,37 \times 0,52 \mathrm{~m}$ e $0,60 \times 0,24 \mathrm{~m}$, para as de maior e de menor volume, respectivamente.

Para a compostagem anaeróbia em biodigestor, foram utilizados baldes de plástico com altura de $0,37 \mathrm{~m}$, diâmetro superior de $0,30 \mathrm{~m}$ e diâmetro inferior de $0,26 \mathrm{~m}$, e capacidade de $20 \mathrm{~L}$, isolados internamente por uma manta térmica (isomanta de polietileno $2 \mathrm{~mm}$ ). Nas tampas foram feitos dois orifícios: um central, para passagem do fio do termômetro digital, e o outro lateral, para a passagem de uma mangueira de silicone para a liberação do gás produzido durante a fermentação. Neste, a extremidade estava depositada dentro de um recipiente com água para evitar a entrada de ar. O conteúdo foi compactado e, em seguida, a tampa foi cuidadosamente vedada com silicone.

A aferição da temperatura interna e do ambiente foi realizada por meio de sensores térmicos de termômetros 
digitais (Termômetro Digital para Ambiente com Relógio Tr 34 Western), alocados no interior (altura média) de todas as repetiçóes. As temperaturas eram anotadas diariamente às $8 \mathrm{e}$ às 17 horas. $\mathrm{O}$ revolvimento manual dos processos aeróbicos (CAM e CAm) ocorriam no momento em que a temperatura interna estabilizava-se por três dias.

As amostras para análise parasitológica, umidade e $\mathrm{pH}$ do composto foram coletadas no início do tratamento, imediatamente antes dos revolvimentos das CAM e CAm, e no final, quando a temperatura interna se estabilizou. As amostras para as análises parasitológicas foram identificadas e armazenadas em caixas de isopor isotérmicas, em temperatura controlada, contendo gelo reciclável. Depois, foram transportadas até o Laboratório de Parasitologia Veterinária no Departamento de Patologia Básica da Universidade Federal do Paraná (UFPR). As amostras para as análises de umidade e $\mathrm{pH}$ foram devidamente lacradas, identificadas e, em seguida, enviadas ao Laboratório de Nutrição Animal do Departamento de Zootecnia da UFPR.

O método utilizado para a cultura das larvas foi o de Roberts; O'sullivan (1950) e, para a identificação das larvas, utilizou-se a chave descrita por Hoffmann (1987) e Madeira de Carvalho (2001). Fez-se a quantificação de larvas na medida em que se realizava a pesagem de cada amostra de coprocultura, permitindo calcular, posteriormente, o número de larvas por grama de resíduos (LGR) existente no composto após a contagem e identificação delas.

O cálculo de LGR foi efetuado utilizando-se a seguinte fórmula:

$\mathrm{LGR}=(\mathrm{N} .10 . \mathrm{V}) / \mathrm{P}$

LGR: larvas por grama resíduo.

$\mathrm{N}$ : Número de larvas em $100 \mu \mathrm{L}$.

V: Volume de água $(\mathrm{mL})$ colocada na placa de Petri, após a coprocultura ser invertida.

P: Peso da amostra (g) para a coprocultura .

A estatística aplicada foi descritiva para as variáveis larvas por grama de fezes no início e no final do experimento, assim com temperatura $\left({ }^{\circ} \mathrm{C}\right)$ máxima entre os tratamentos. Procedeu-se a Análise da Variância (Anova) em blocos ao acaso, utilizando-se o software estatístico SAS (1996), e o mesmo software para o teste de médias (Tukey), a 5\% de probabilidade.

\section{RESULTADOS E DISCUSSÃO}

A temperatura mínima, máxima e média do ambiente no período experimental foi de $12^{\circ} \mathrm{C} ; 25^{\circ} \mathrm{C}$ e $18,5^{\circ} \mathrm{C}$, sendo que a temperatura interna das composteiras teve média inicial de $23,5^{\circ} \mathrm{C}$, e a final estabilizada em $17,6^{\circ} \mathrm{C}(\mathrm{CASRm}) ; 23,4^{\circ} \mathrm{C}$ (CASRM); $18,3^{\circ} \mathrm{C}(\mathrm{CAm}) ; 22,9^{\circ} \mathrm{C}(\mathrm{CAM})$ e $18,5^{\circ} \mathrm{C}(\mathrm{CF})$.
O pico de elevaçáo ocorreu no primeiro dia do período experimental, quando as CASRM e as CAM apresentaram temperatura de $60,7^{\circ} \mathrm{C}$ e $58,8^{\circ} \mathrm{C}$, e as CASRm, CAm e CF, de $30,9^{\circ} \mathrm{C} ; 30,4^{\circ} \mathrm{C}$ e $30,03^{\circ} \mathrm{C}$; a temperatura mínima interna identificada foi de $13,5^{\circ} \mathrm{C}$ (CASRm); $20,3^{\circ} \mathrm{C}$ (CASRM); $15,8^{\circ} \mathrm{C}(\mathrm{CAm}) ; 20,2^{\circ} \mathrm{C}(\mathrm{CAM})$ e $12,2^{\circ} \mathrm{C}(\mathrm{CF})$. Nas primeiras 24 horas houve um aumento de aproximadamente $8^{\circ} \mathrm{C}$ na massa para os tratamentos CASRM e CAM, mantendo-se superior a $50^{\circ} \mathrm{C}$ somente nos três primeiros dias, e diminuindo $3^{\circ} \mathrm{C}$ nos demais (Fig. 1). Após 40 dias, o ciclo de compostagem foi finalizado. Como base do término, considerou-se a estabilizaçấo de cinco dias das temperaturas dos tratamentos.

De acordo com Herbets et al. (2005), a temperatura é considerada como o fator determinante para o processo, pois diferentes temperaturas promovem o desenvolvimento de diferentes micro-organismos. É a variável mais utilizada para realizar o monitoramento e a evoluçáo da compostagem, além de promover a eliminação total ou parcial de muitos micro-organismos patogênicos. Estes mesmos autores descrevem que temperaturas entre 45 e $70^{\circ} \mathrm{C}$ fazem com que o processo de decomposição seja mais eficiente, considerando a temperatura ótima como sendo a de $60^{\circ} \mathrm{C}$ para a eliminação da maioria dos patógenos.

VALENTE (2008), que trabalhou com porcentagem de diferentes resíduos de abate de animais de produção, palha e serragem, mostrou que o tamanho das leiras, grandes e pequenas, influencia diretamente na temperatura, não atingindo temperaturas elevadas mesmo na fase inicial do processo. Entretanto, neste trabalho, os tratamentos CASRM e CAM com altura e largura de aproximadamente de 1,37 x $0,52 \mathrm{~m}$, apresentaram temperaturas que chegaram a aproximadamente $60^{\circ} \mathrm{C}$. Isso indica que, mesmo em proporções diferentes do recomendado por KIeHL (2004), segundo o qual altura e largura da composteira devem estar entre $1,5 \times 1,8 \mathrm{~m}$, neste ensaio apenas as temperaturas para CASRM e CAM chegaram a ser consideradas próximas do ótimo.

Em relação aos outros tratamentos, CASRm e CAm, com altura e largura de 0,60 x 0,24 m, as temperaturas máximas ficaram em 30,9 e $30,4^{\circ} \mathrm{C}$. Isso se deve ao fato de que houve maior troca térmica entre os montes e o ambiente, o que dificultou a elevação da temperatura. Além do tamanho, a época do ano em que se realizou o experimento influenciou para que as temperaturas ficassem abaixo do ideal, já que a média da temperatura ambiente náo passou de $18^{\circ} \mathrm{C}$, sendo a máxima e a mínima de 25 e $11^{\circ} \mathrm{C}$, respectivamente. Com esses dados, é possível afirmar que leira/montes de compostagem devem apresentar altura mínima para que alcancem temperaturas acima de $45^{\circ} \mathrm{C}$. VAlente et al. (2009) afirmaram que, de acordo com o material a ser compostado, a altura das leiras deve ser estabelecida em no mínimo $0,80 \mathrm{~m}$; abaixo disso não existem condiçôes adequadas para a formaçáo e a manutenção da temperatura.

Porém, o controle do tamanho de leira/montes, temperatura e umidade náo é visto como uma prática usual na maioria 
das propriedades. A existência de manejo inadequado, como a disposição dos resíduos em locais inapropriados, e a falta de interesse em controlar esses principais fatores interferem diretamente no processo da compostagem. A presença de patógenos que possam causar problemas tanto ao homem como aos animais acaba sendo inevitável, uma vez que todo o processo acaba não sendo suficiente para eliminá-los.

De acordo com os resultados obtidos, a presença de larvas infectantes de terceiro estágio (L3) de Strongylus spp. em número por grama de resíduo (LGR) na amostra inicial do resíduo foi de 25,3. Após a finalização do experimento, a quantificação de L3 na parte interna da massa para cada tratamento foi de 18,6 (CASRm); 2,3 (CASRM); 3,3 (CAm); 0,7 (CAM) e 0,0 (CF). Já na regiáo superficial da massa para todos os tratamentos não foi possível verificar a presença de larvas. Houve diferença estatística $(\mathrm{p}<0,05)$ no número de larvas por grama de fezes no início e no final das amostras retiradas da região central e superficial de cada composteira, respectiva aos tratamentos, exceto para o tratamento $\mathrm{CF}$, que não apresentou diferença estatística $(\mathrm{p}>0,05)$ entre a regiáo central e a superficial na última amostragem (Tabela 1).

A presença de parasitos na parte central da massa (dos tratamentos) e a eliminação de ovos viáveis de Strongylus spp. náo ocorreram de forma efetiva até o terceiro dia, por mais que as temperaturas nas CASRM E CAM se apresentassem superiores a $50^{\circ} \mathrm{C}$. Entretanto, CARRINGTON (2001) sugeriu que sete minutos a $70^{\circ} \mathrm{C}, 30$ minutos a $65^{\circ} \mathrm{C}$, duas horas a $60^{\circ} \mathrm{C}, 15$ horas a $55^{\circ} \mathrm{C}$ ou três dias a $50^{\circ} \mathrm{C}$ são suficientes para a inativaçáo de ovos de helmintos.

No caso da CAM, houve diminuição de quase 57,7\% das L3 na primeira semana de tratamento, e no final a redução foi de $97 \%$. Resultados semelhantes foram obtidos por SCHROtTle (1955), que relacionava a sobrevivência das larvas infectantes de Strongylus spp. à temperatura de $40^{\circ} \mathrm{C}$ em compostagem. $\mathrm{O}$ autor obteve resultados de eliminação das L3 somente após 35 dias de tratamento. Este mesmo autor afirma que o aumento da temperatura para $50^{\circ} \mathrm{C}$ diminuiu o tempo de sobrevivência em um terço, diferentemente CAM, em que a eliminaçáo foi maior do que 50\%.

BRIGGs et al. (2004) afirmaram que os ovos de helmintos não eclodem abaixo de $7{ }^{\circ} \mathrm{C}$, ao passo que, acima de $30^{\circ} \mathrm{C}$ ou $38^{\circ} \mathrm{C}$ (Kuzmina et al., 2006; Couto et al., 2008) as formas L1 morrem rapidamente, não suportando o calor tấo acentuado. Isso possivelmente deve ter ocorrido também para o tratamento CASRM, para o qual se obteve redução de $90 \%$ de L1 ao final de 40 dias de tratamento, mas que não se aplica para o tratamento CASRm, que ainda apresentava elevado número de larvas na análise final. HAUG (1993) também mencionou que os patógenos são destruídos ou controlados por outros fatores, como relaçóes ecológicas existentes na massa de compostagem, por exemplo, a competição.

De acordo com Madeira de Carvalho et al. (2005), a atividade das L3 aumenta consideravelmente com o aumento
Tabela 1. Larvas por grama de resíduo no início e no final da região central e superficial das composteiras, respectivas aos tratamentos.

\begin{tabular}{lccc} 
& \multicolumn{3}{c}{ LGR $^{*}$} \\
\cline { 2 - 4 } Tratamentos & Início & \multicolumn{2}{c}{ Final } \\
\cline { 2 - 4 } & & Centro & Superfície \\
CASRm & $25,3 \mathrm{a}$ & $18,6 \mathrm{~b}$ & O c \\
\hline CASRM & $25,3 \mathrm{a}$ & $2,3 \mathrm{~b}$ & O c \\
\hline CAm & $25,3 \mathrm{a}$ & $3,3 \mathrm{~b}$ & O c \\
\hline CAM & $25,3 \mathrm{a}$ & O,7 b & O c \\
\hline CF & $25,3 \mathrm{a}$ & O b & O b \\
\hline
\end{tabular}

CAm: aberta com revolvimento em menor volume; CAM: aberta com revolvimento em maior volume; CASRm: aberta sem revolvimento em menor volume, CASRm: aberta sem revolvimento em maior volume e CF:anaeróbica em biodigestor.

*LGR: larvas por grama de resíduo; Valores seguidos da mesma letra na mesma linha não diferem significativamente para o teste de Tukey, a $5 \%$ de probabilidade.

da temperatura, esgotando rapidamente suas reservas. Por este motivo, altas temperaturas promovem a mortalidade elevada em um curto espaço de tempo, ao passo que baixas temperaturas permitem sua sobrevivência durante meses.

Na primeira semana, para a CAm houve aumento de 18\% de eclosão dos ovos de helmintos, provavelmente devido à temperatura interna, que se manteve entre 19 e $25^{\circ} \mathrm{C}$, o que não foi suficiente para sua eliminação, mas sim para seu desenvolvimento. Hutchinson et al. (1989) consideraram como temperatura ótima para o desenvolvimento de ciatostomíneos a faixa de $10 \mathrm{a} 33^{\circ} \mathrm{C}$, o que não explicaria, ao final deste tratamento, a eliminaçáo de $87 \%$ dos helmintos, sendo que a temperatura máxima foi de $30,4^{\circ} \mathrm{C}$. É importante observar que as condiçôes ideais para o desenvolvimento das larvas não são as ideais para sua sobrevivência (MAdeIRA de CARVAlHo, 2001).

Em relação ao tratamento CASRm, a diminuição na contagem das larvas infectantes ao final, na região interna do composto, foi de $26 \%$. Nesse caso, a baixa eliminação pode ter sido causada pelas baixas temperaturas do início ao fim da compostagem, que, além de influenciarem na sobrevivência e no desenvolvimento larvar, também influenciaram no seu comportamento migratório: da extremidade para o interior da composteira. A umidade na parte superficial, que era de $17,6 \%$, foi muito importante para que ocorresse essa migração de larvas para o interior do composto, que apresentava umidade de 54,9\%, indicando o grande número na amostra final. Alguns autores afirmaram que, em condiçōes desfavoráveis, as L3 migram para determinadas profundidades do solo, buscando refúgio (LYAKU et al., 1988). Outra consideração em relação aos helmintos são suas adaptaçôes morfofisiológicas, que caracterizam alta resistência aos processos de sanitização (ANDReoli; Pinto, 2001).

Neste trabalho, o único tratamento que apresentou eliminação de $100 \%$ das L3 foi a compostagem anaeróbia. Resultados semelhantes aos deste trabalho foram observados por FURLONG; Padilha (1996), com nematoides gastrointestinais de bovinos, no qual o efeito inativante da anaerobiose chegou a quase $100 \%$ 


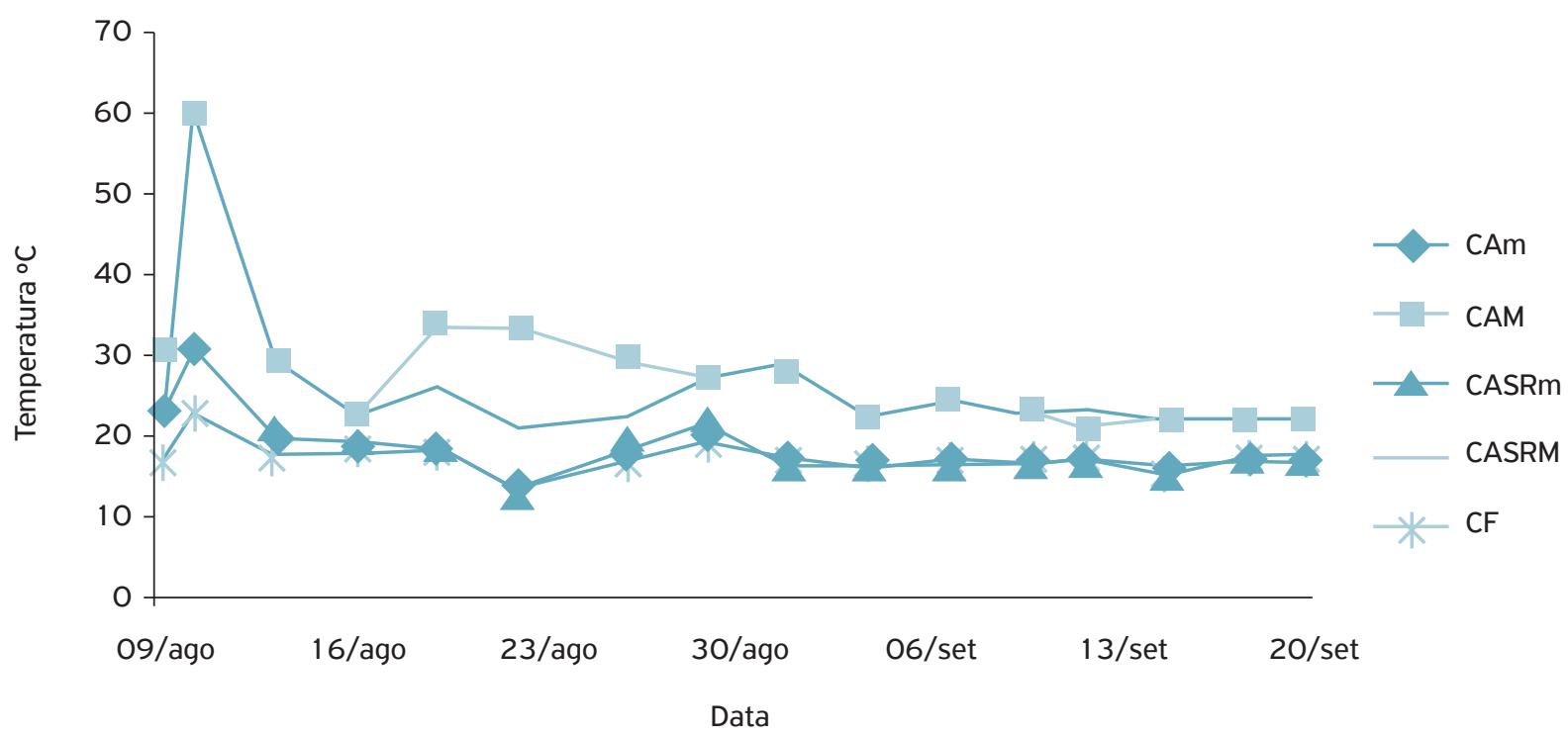

CAm: aberta com revolvimento em menor volume; CAM: aberta com revolvimento em maior volume; CASRm: aberta sem revolvimento em menor volume, CASRm: aberta sem revolvimento em maior volume e CF:anaeróbica em biodigestor.

Figura 1. Temperatura média da massa interna observada durante o processo de compostagem do material.

em um período de 56 dias. Porém, em outro trabalho, Amaral et al. (2004), avaliando o processo de biodigestáo anaeróbia para tratamento de dejetos de bovinos, obtiveram resultados positivos para larvas L3 de Haemonchus spp, Oesophagostomum spp e Cooperia spp., mesmo após 40 dias de tempo de retenção. Segundo Olson; NANSEN (1987), a digestáo anaeróbia mesofilica $\left(35^{\circ} \mathrm{C}\right)$ e a termofílica $\left(53^{\circ} \mathrm{C}\right)$ aceleraram o processo de inativação de nematoides em relação ao tempo de sobrevivência desses parasitos no armazenamento convencional. CHERNICHARO et al. (2003) afirmaram que, em digestores anaeróbios, ovos de helmintos se apresentam como os mais resistentes, por isso, especificamente no que se refere à eficiência de sanitização, ovos de helmintos têm sido recorrentemente empregados como principais indicadores da eficiência de tal processo. Portanto, a sanitização do tratamento $\mathrm{CF}$ foi eficiente, pois no composto não foram identificados ovos e L3 de helmintos.

$\mathrm{Na}$ parte superficial das composteiras, na amostra final para todos os tratamentos, os achados de L3 foram negativos. O principal fator que contribuiu para este resultado, além da temperatura ambiente, que interferia diretamente nesta regiāo dos montes, foi a umidade. De acordo com Couto et al. (2008), para que haja desenvolvimento larvar, a umidade mínima deve ser de $30 \%$. No caso dos tratamentos CASRm, CASRM e CAm, a umidade era baixa, de 17,55\%; 20,27\% e $29,41 \%$, o que contribuiu para que as larvas migrassem para o interior da massa, que apresentava umidade superior a $40 \%$, ou porque a sensibilidade de ovos e larvas de helmintos apresentassem dessecação, quando encontrados no meio (REY, 1991).

Os valores de $\mathrm{pH}$ neste trabalho não foram suficientes para a eliminação de ovos e larvas de Strongylus spp. Entretanto, alguns autores (ILHNFELD et al., 1999) citaram-no como eficiente ferramenta para destruição e/ou inativaçáo, e também como o principal responsável pela sanitização absoluta do composto, com relação aos ovos de helminto com valores de $\mathrm{pH}$ acima de 10 por um período de 60 dias.

Para o eficaz controle ou eliminação de parasitos nesses tipos de processos aos quais materiais com potencial de contaminação estáo sendo submetidos, a presença de temperaturas elevadas é imprescindível, além do controle de umidade, tamanho dos montes e o próprio revolvimento. É necessário padronizar o manejo de resíduos provenientes de centros de treinamento e realizar mais estudos a respeito das melhores formas de eliminação dos parasitas.

\section{CONCLUSÃO}

Os resultados indicam que com a simples disposição dos resíduos de cocheira sem manejo adequado e em pequenos volumes, não há eliminação total de ovos e larvas de parasitas.

Fatores como revolvimento e tamanho dos montes mostraram-se essenciais para a eliminação dos ovos de Strongylus spp.

O processo de biodigestáo anaeróbia em biodigestor mostrou-se ,mais eficiente em comparaçấo aos processos de compostagem abertos, com ou sem revolvimento.

\section{AGRADECIMENTOS}

Aos professores João Ricardo Dittrich e Edilene Alcântara de Castro, da Universidade Federal do Paraná, Emanuel Orestes da Silveira e ao REUNI (Reestruturação e Expansão das Universidades Federais), pela concessão de bolsa de produtividade em pesquisa. 


\section{REFERÊNCIAS}

AMARAL, C.M.C.; AMARAL, L.A.; LUCAS JUNIOR, J.; NASCIMENTO, A.A.; FERREIRA, D.S.; MACHADO, M.R.F. Biodigestão anaeróbia de dejetos de bovinos leiteiros submetidos a diferentes tempos de retenção hidráulica. Ciência Rural, Santa Maria, v.34, p.18971902, 2004.

ANDREOLI, C.V.; PINTO, M.A.T. Resíduos sólidos do saneamento: processamento, reciclagem e disposição final. Rio de Janeiro: RIMA/ABES (PROSAB), 2001. 282p.

BRIGGS, K.; REINEMEYER, C.; FRENCH, D.; KAPLAN, R. Strongyles: the worst of the worms. The Horse, p. 15-18, 2004.

CARRINGTON, E.G. Evaluation of sludge treatments for pathogen reduction. Final Report. Luxembourg: European Communities, p.44, 2001.

COUTO, M.; QUINELATO, S.; SANTOS, C.; SOUZA, L.; SAMPAIO, I. Environmental influence in cyathostominae ecology. Veterinarni Medicina, v.53, p.243-249, 2008.

FURLONG, J.; PADILHA, T. Viabilidade de ovos de nematódeos gastrintestinais de bovinos após passagem em biodigestor anaeróbio. Ciência Rural, Santa Maria, v.26, p.269-271, 1996.

HAUG, R.T. The practical Handbook of Composting Engineering. United States of America: Lewis Publishers, 1993.

HERBETS, R.A., COELHO, C.R.A.; MILETTI, L.C.; MENDONÇA, M.M. Compostagem de resíduos sólidos orgânicos: aspectos biotecnológicos Health and Environment Journal, v.6, n. 1, p.41-50, 2005.

HOFFMANN, R.P. Diagnóstico de Parasitismo Veterinário. Porto Alegre: Editora Sulina. 1987.

HUTCHINSON, G.W.; ABBA, S.A.; MFITILODZE, M.W. Seasonal translation of equine strongyle infective larvae to herbage in tropical Australia. Veterinary Parasitology, v.33, n.3-4, p.251-263, 1989.

ILHNFELD, R.G.K.; ANDREOLI, C.V.; LARA, A.I. Higienização do lodo de esgoto. In: Programa de Pesquisa em Saneamento Básico. Uso e Manejo do Lodo de Esgoto na Agricultura. Rio de Janeiro: PROSAB, Programa de Pesquisa em Saneamento Básico, p.97. 1999.

KIEHL, E.J. Manual de compostagem: maturação e qualidade do composto. $4^{\text {a }}$ ed. Piracicaba, 2004. 173p.

KUZMINA, T.A.; KUZMIN, Y.I.; KHARCHENKO, V.A. Field study on the survival, migration and overwintering of infective larvae of horse strongyles on pasture in central Ukraine. Veterinary Parasitology, v.141, p.264-272, 2006.

LYAKU, J.R.S.; MONRAD, J.; KASSUKU, A.A. Larval ecology of bovine strongilid worms in tropical soils. Tropical Animal Health of Production, v.20, n.1, p.190-192, 1998.
LOVATTO, P.A.; OLIVEIRA, V.; EBERT, A.R. Suinocultura Geral. Santa Maria: UFSM. 1997.

MADEIRA DE CARVALHO, L.M. Epidemiologia e controlo da estrongilidose em diferentes sistemas de produção equina em Portugal. 2001. Tese (Dissertação de Doutoramento) Faculdade de Medicina Veterinária da Universidade Técnica de Lisboa. 2001.

MADEIRA DE CARVALHO, L.M.; FAZENDEIRO, I.M.; AFONSOROQUE, M.M. Estudo do padrão sazonal dos ovos e larvas de estrongilídeos do cavalo numa exploração do Ribatejo, através da contaminação de parcelas experimentais em pastagens espontâneas de sequeiro. In: IX CONGRESSO IBÉRICO DE PARASITOLOGIA Anais. Faculdade de Farmácia, Universidade de Coimbra, v.12, 2005 285p.

OLSON, J.E.; NANSEN, P. Inactivation of some parasites by anaerobic digestion of cattle slurry. Biological Wastes, Fayetteville, v.22, p.107-114, 1987.

PEREIRA NETO, J.T.; LELIS, M.P.N.A contaminação biológica na compostagem. In: $21^{\circ}$ CONGRESSO BRASILEIRO DE ENGENHARIA SANITÁRIA E AMBIENTAL. Anais. João Pessoa: ABES, 2001. p.1-6.

REY, L. Parasitologia. Parasitos e doenças parasitárias do homem nas Américas e na África. $2^{2}$ ed. Rio de Janeiro: Guanabara Koogan S. A., $1991.731 \mathrm{p}$.

ROBERTS, F.H.S.; O'SULLIVAN, P.J. Methods for egg counts and larval cultures for strongylus infecting the gastro-intestinal tract of cattle. Australian Journal of Agriculture Ressearch, p. 99-102, 1950

SAS. Statistical Analysis System Institute. SAS/STAT. User's guide, version 6.11. $4^{\text {th }}$ ed.cry, v.2, p.842, 1996.

SCHROTTLE, H. Ueber die Haltbarkeit von Wurmeier und Wurlarven im Dunger. 1955. (Dissertação) - Veterinary Medicine at University Munchen. 1955.

STRAUCH, D. Animal production and environmental health Science. (World Animal Science B6). Amsterdam: Elsevier Science Publishers BV, 1987. 324p.

VALENTE, B.S.; XAVIER, E.G.; MORSELLI, T.B.G.A.; JAHNKE, D.S.; BRUM JR, B.de.S.; CABRERA, B.R.; MORAES, P.O.; LOPES, D.C.N. Fatores que afetam o desenvolvimento da compostagem de resíduos orgânicos. Archivos de Zootecnia, v.58, p.5985, 2009

VALENTE, B.S. Tratamento de carcaças avícolas através da compostagem. 2008. 154f. Dissertação (Mestrado em Zootecnia) Faculdade de Agronomia Eliseu Maciel da Universidade Federal de Pelotas. Pelotas, 2008. 